\title{
1. Introduction to Handbook on Strategic Environmental Assessment
}

\author{
Thomas B. Fischer and Ainhoa González
}

\section{INTRODUCTION}

Strategic Environmental Assessment (SEA), as the environmental assessment of policies, plans and programmes, first emerged in the late 1980s (Fischer 1999). ${ }^{1}$ The associated term is said to have been coined during discussions in the then Environmental Impact Assessment (EIA) Centre at the University of Manchester. ${ }^{2}$ However, the need for the assessment of environmental impacts above the project level was discussed and stressed much earlier; for example, by O'Riordan and Sewell (1981).

The United States (US) National Environmental Policy Act (NEPA) from 1970, the first piece of environmental assessment legislation globally, did not actually distinguish between projects on the one hand and policies, plans and programmes on the other, but simply referred to 'actions' instead. However, in US practice, initially NEPA-based assessments were used mainly for projects. Programmatic environmental impact statements (PEIS) became the term used in the USA for environmental assessments above the project level later, and initially PEISs were applied only infrequently (Sigal \& Webb 1989). Reference to the first PEIS on Scopus (the largest abstract and citation database of peer-reviewed literature) is from 1980, referring to offshore natural gas development in Lake Erie (Marks et al. 1980).

SEA became firmly rooted in the vocabulary of those involved in plan-and programme-making in 2004 when European Directive 2001/42/EC on the assessment of the effects of certain plans and programmes on the environment (published in 2001) had to be transposed in the then 25 European Union (EU) member states. Whilst the Directive does not use the term 'SEA', it is routinely called 'SEA Directive' (including by the European Commission itself). Importantly, policies are not covered by the SEA Directive.

SEA has become widely applied globally and there are now over 60 countries with some formal SEA requirements. Besides the $27 \mathrm{EU}$ member states to which the SEA Directive applies (eight of which are discussed in Chapter 20 by Koshkar et al., 2021) and several others are covered in Chapters 2-7 and 10-17), these also include another 11 countries that signed the Protocol on SEA to the Convention on Environmental Impact Assessment in a Transboundary Context (Espoo Convention, 2003; fully ratified by 9 non-EU countries ${ }^{3}$ ). Other countries with requirements for SEA-type assessments above the project level include Australia (see

\footnotetext{
1 The term itself was used earlier, i.e. in a 1974 paper on environmental modelling (see House 1974). However, this had a different meaning from today's understanding.

2 The University of Manchester's EIA Centre was in existence from the mid-1980s to the early 2000s.

3 See https://treaties.un.org/Pages/ViewDetails.aspx?src=TREATY\&mtdsg_no=XXVII-4-b\& chapter=27\&lang=en.
} 
Chapter 18 by Burdett and Cameron, 2021), Bhutan ${ }^{4}$ (covered in Chapter 9 by Annandale et al., 2021), Brazil (Chapter 23 by Montaño et al., 2021), Cambodia, Canada (Chapter 19 by Noble, 2021), Chile (Chapter 24 by Jiliberto, 2021), China (Chapter 9 by Annandale et al., 2021), Ghana, Guinea-Bissau, Kenya, the Republic of Korea, Malaysia, New Zealand (Chapter 21 by Morgan and Taylor, 2021), Pakistan (for Khyber Pakhtunkhwa Province, see also Chapter 9), Thailand (Chapter 26 by Chanchitpricha et al., 2021), Ukraine, the United States of America (mentioned in Chapter 12 by Geißler et al., 2021) and Vietnam (covered in Chapter 9). There are also countries with emerging guidelines, including e.g. South Africa (see Chapter 22 by Retief et al., 2021), Lao and Indonesia (for both, see Chapter 9). Furthermore, a number of central and south American countries have also been said to have introduced some formal requirements, including Bolivia, Costa Rica, El Salvador, Guatemala, Honduras, Peru and Uruguay (Tiffer-Sotomayor et al. 2015). However, the extent of associated SEA practice has remained unclear.

In addition, there is some substantial voluntary application and practice of SEA in other developing countries, frequently driven by requirements of development banks and organizations (including, for example, the World Bank, the Inter-American Development Bank and the Asian Development Bank). In this context, over 150 separate SEA initiatives in 2012 were tracked by the Organisation for Economic Co-operation and Development (OECD) Development Co-operation Directorate (OECD-DAC) Environment SEA Task Team, which regularly surveys SEA activities in developing countries (Dalal-Clayton 2013).

\section{EVOLVING UNDERSTANDING OF SEA}

Initially, when SEA emerged, it was perceived as the application of a project EIA process, applying an approach which focuses on impacts and effects of draft proposals and associated methods to strategic initiatives. However, it quickly became apparent that the higher the level of the strategic action, the less applicable EIA-based approaches tended to be. For example, a conceptual policy which aims at developing a broad development vision for a certain area will need methods and techniques that are likely to be more discursive and qualitative, rather than quantitative. Quantitative approaches are more frequently used under EIA procedures (see Chapter 4 by Partidário, 2021; see also Chapter 27 by Fischer and González, 2021).

SEA subsequently became increasingly approached as a "framework" rather than just a process (as discussed by e.g. Fischer 1999, Gosling 1999 and Jansson 2000), with other vital elements being of crucial importance for an effective application, including the comprehensive coverage of tasks, alternatives and questions typically addressed at different tiers (i.e. at policy, plan and programme levels), as well as other contextual and institutional aspects (e.g. capacity, transparency, participatory arrangements; see Chapters 7 and 8 on SEA effectiveness by Thérivel and González, 2021, and Fischer and Retief, 2021). As a consequence, the validity of a particular SEA approach can be regarded as being dependent on the characteristics of the specific situation of application. Where SEA is more routinely applied, e.g. in statutory land-use planning, a structured process as used in EIA can be appropriate. In policy situations, where vested interests are not too strong and power gradients not too steep, round

4 Whilst Bhutan introduced SEA legislation in 2002, subsequently, this was not implemented (OECD 2012). 
table approaches, involving multiple stakeholders might be a suitable approach (Fischer et al. 2010; González et al. 2019). In more recent times, SEA has also been presented as the vehicle to drive sustainable development and attain sustainable development goals (Fischer 2020; González et al. 2020; Morrison-Saunders et al. 2019; Partidário 2015).

Over the past decade, the development of SEA practice internationally has been particularly influenced by the European SEA Directive (EC 2001) and the UNECE (Kiev) protocol on SEA to the Espoo Convention (UNECE 2003). The Directive has not only made SEA a routine application for numerous spatial and sectoral plans and programmes in the $27 \mathrm{EU}$ member states, it has also heavily influenced the development of SEA in other countries and international institutions, as well as development banks. It is likely that several thousands of SEAs have been conducted in EU member states alone since 2004 (EC 2009; Fischer 2007). The Directive's requirements revolve around an assessment process which looks similar to a typical EIA process, with procedural stages including screening (is SEA necessary?), scoping (what should it cover, including environmental aspects, types of impacts and alternatives?), analysis and evaluation of potential significant effects, the production of an SEA report, consultation and public participation, taking a decision in the light of the evidence produced, making recommendations to mitigate identified potential adverse effects, as well as monitoring and follow-up. In different SEA systems throughout the world, these stages are covered to varying extents and quality. This, together with numerous other aspects of SEA, is elaborated on in this book.

\section{EXISTING SEA RESEARCH AND LITERATURE}

In addition to the rapidly growing application of SEA, related research activities and outputs have also increased substantially over the past few decades. The first comprehensive review of SEA research and related publication was conducted by Fischer and Onyango (2012). Looking at the three main journals for SEA publications (Environmental Impact Assessment Review (EIAR), Impact Assessment and Project Appraisal (IAPA) and Journal of Environmental Assessment Policy and Management (JEAPM)), based on a Scopus search (SEA in the title/ keywords/abstract) they found that 250 papers dealing with SEA had been published over 19 years between 1993 and 2011. Doing the same search eight years later in 2020, 465 papers are identified that were published between 1993 and 2019 (Figure 1.1). Another 13 papers had been published in 2020 by June. This means the number of papers since 2011 has nearly doubled.

With regard to books dealing with SEA, 21 are listed on Scopus with SEA in the title, abstract and/or keywords (with a total of 71 SEA chapters). Of these, nine are dedicated books on SEA (some of the early SEA books are not listed on Scopus, though, e.g. Fischer 2002; Therivel et al. 1992; Therivel \& Partidário 1996). The last major SEA book was published in 2016 (Sadler \& Dusik 2016). However, contributions in this date back to the 2011 SEA symposium of the International Association for Impact Assessment (IAIA) in Prague, which means there has been a decade now without any up-to-date SEA book available.

SEA research has focused on many different sectors and countries/regions of application. Most widely reported has been practice in spatial and land-use planning (see Chapter 10 by González, 2021), followed by transport (see Chapter 11 by Faith-Ell and Fischer, 2021) and energy (see Chapter 12 by Geißler et al., 2021). Whilst practices in other sectors have also 


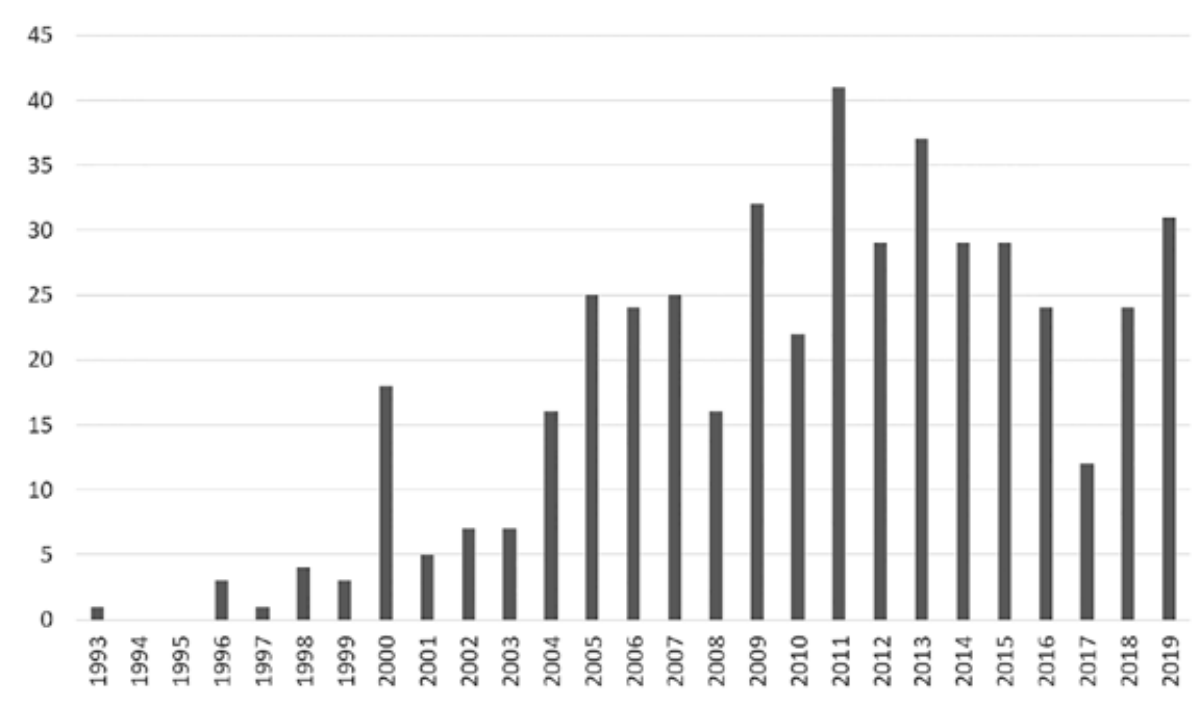

Figure $1.1 \quad$ Number of SEA papers published in EIAR, IAPA and JEAPM

been reported on (e.g. waste and minerals extraction), this has been more sporadic (see e.g. Fischer et al. 2011 and Porto Silva Cavalcanti and La Rovère 2011). We include water in Chapter 13 (by Mustow, 2021) as an example. With regard to particular countries/regions, most publications have been on those where SEA is formally required, in particular the EU (see Chapter 20 by Koshkar et al., 2021, on eight EU member states), Australia (see Chapter 18 by Burdett and Cameron, 2021), Canada (see Chapter 19 by Noble, 2021) and New Zealand (see Chapter 21 by Morgan and Taylor, 2021). Chile is a country with formal requirements which is rarely reported on (see Chapter 24 by Jiliberto, 2021). On the other hand, whilst South Africa and Brazil currently do not have formal requirements, they have been more visible in the professional literature (see Chapter 22 by Retief et al., 2021 on South Africa, and Chapter 23 by Montaño et al., 2021 on Brazil). However, countries without any formal SEA requirements tend to be represented less frequently. This includes e.g. India (see Chapter 25 by Jha-Thakur and Rajvanshi, 2021) and Thailand (see Chapter 26 by Chanchitpritcha et al., 2021). Finally, integration in and through SEA has received a considerable amount of attention. Aspects for integration covered in this book include protected areas (see Chapter 15 by Scott, 2021), climate change (see Chapter 16 by O'Mahony, 2021), ecosystem services (see Chapter 17 by Slootweg, 2021) and health (see Chapter 14 by Fischer et al., 2021).

\section{ABOUT THIS BOOK}

The aim of this book is to provide a comprehensive and up-to-date overview of the theory and practice of SEA. In this context, different conceptual approaches and applications of SEA are highlighted and discussed. A key objective is to help researchers and practitioners locate a particular SEA application within the overall 'jigsaw' comprising SEA, thus allowing development of an understanding of the specific purpose, scope, benefits and limitation of a particular approach. 
The starting point for the editors when engaging with the book idea was that there is no one-size-fits all approach to SEA and that what is emerging is an overall 'SEA system', consisting of - at least - the following approaches:

1. SEA supports the development of an overall environmentally sustainable vision for e.g. a global initiative, a continent, a country, a region, municipality or local community: this has also been referred to as the 'strategic approach' to SEA.

2. SEA supports the drafting of policy (which has been referred to as e.g. 'regulatory impact assessment'; other policy-type SEA approaches include e.g. territorial impact assessment).

3. SEA is EIA process-based, which usually supports the preparation of plans and programmes, particularly at the local level.

4. SEA supports the creation of consensus of future action in situations where there is openness towards outcomes and acting strategies (a possible application may be the round-table approach).

5. SEA is understood not as a one-off process but as a system, which in order to be effective, needs to systematically cover policies, plans and programmes.

6. SEA is defined by specific techniques, e.g. geographic information system (GIS)-driven, used, for example, when identifying suitable locations, or matrix-driven when pursuing an objectives-led approach.

What is of particular importance is that these different approaches are not mutually exclusive, but may be applied in combination. They do fulfil certain purposes, though, and knowing the specific context within which SEA is supposed to be applied can help the user to pick an approach which is suited to a particular application. One of the purposes of the book, therefore, is to reflect on the possibility of developing an SEA theory, to which we will come back in Chapter 27 (Fischer and González, 2021).

All the approaches listed above are presented and discussed throughout the book. For example, with regard to approach 1, Chapter 4 by Partidário (2021) focuses in its entirety on what may be involved in using SEA to think strategically about the impacts of development initiatives and sustainability. Furthermore, several other chapters cover parts of what is important when making SEA a tool for sustainable development (e.g. Chapter 10 on land-use planning by González (2021), Chapter 11 on transport SEA by Faith-Ell and Fischer (2021) and Chapter 14 on different types of integration by Fischer et al. (2021).

With regard to approach 2, Chapter 5 by Marot et al. (2021) is dedicated to territorial impact assessment (TIA), providing insights on the practical application of this policy SEA-type tool, which is used in the EU. Furthermore, Chapter 3 by Hayes and Fischer (2021) on objectives-led SEA also partly focuses on this approach. Chapter 2 by Rehhausen et al. (2021) focuses on EIA-based SEA, and therefore addresses approach 3. This particular approach remains the most widely applied form of SEA, particularly in EU member states. This is also evident in Chapter 9 by Annandale et al. (2021) on SEA guidelines. Furthermore, various other chapters cover relevant aspects.

Approach 4 is in parts connected with approach 1, and Chapter 4 (Partidário, 2021) is therefore again of relevance, as is Chapter 2 (Rehhausen et al., 2021). Furthermore, Chapters 14-17 are of particular relevance with regard to consensus building. This includes the consideration of key aspects, such as 'types of integration' (Chapter 14 by Fischer et al., 2021); 'appropriate assessment' and SEA (Chapter 15 by Scott, 2021); 'climate change and SEA' (Chapter 16 by O'Mahony, 2021); and 'ecosystem services and SEA' (Chapter 17 by Slootweg, 2021). 
Chapter 11 on transport planning (Faith-Ell and Fischer, 2021) is related to what is covered in approach 5. It is also covered in Chapter 14 on different types of integration (Fischer et al., 2021). Generally speaking, various aspects of a systems approach are covered in all chapters of this book.

Finally, approach 6 is reflected in Chapter 6 (González and Geneletti, 2021) on GIS-based SEA. Furthermore, an objectives-led approach is described in Chapter 3 (Hayes and Fischer, 2021) and related examples are also presented and discussed in Chapter 10 (González, 2021). A number of other chapters cover aspects of specific techniques used in different situational applications.

This book consists of a total of 27 chapters, presented in five main parts. Part I comprises this introductory chapter. Part II consists of five chapters, representing different approaches to SEA. In the three chapters in Part III, various issues of SEA effectiveness are addressed and discussed. In the 17 subsequent chapters of Part IV, SEA practices with regard to sectoral applications, integration aspects and country/region-specific applications of SEA are portrayed. Finally, in Part V, aspects of a possible SEA theory are introduced.

\section{REFERENCES}

Annandale, D., Montaño, M., Fischer, T.B., Purcell, C., Coles, J. and Aung, T. 2021. Guidelines for strategic environmental assessment in developing countries: examples from Asia, in: Fischer, T.B. and González, A. (eds), Handbook on Strategic Environmental Assessment, Cheltenham: Edward Elgar (chapter 9).

Burdett, T. and Cameron, C. 2021. Strategic environmental assessment in Australia, in: Fischer, T.B. and González, A. (eds), Handbook on Strategic Environmental Assessment, Cheltenham: Edward Elgar (chapter 18).

Chanchitpricha, C., Swangjang, K. and Morrison-Saunders, A. 2021. Addressing the spectrum of strategic environmental assessment potential: evolving practice in Thailand and its effectiveness, in: Fischer, T.B. and González, A. (eds), Handbook on Strategic Environmental Assessment, Cheltenham: Edward Elgar (chapter 26).

Dalal-Clayton, B. 2013. The Role of Strategic Environmental Assessment in Promoting a Green Economy, IIED, London.

EC [European Commission]. 2001. Directive 2001/42/EC on the assessment of the effects of certain plans and programmes on the environment. Brussels: European Commission. Official Journal of the European Union, L197/30, 21.7.2001.

EC [European Commission]. 2009. Report from the Commission to the Council, the European Parliament, the European Economic and Social Committee and the Committee of the Regions on the application and effectiveness of the Directive on Strategic Environmental Assessment (Directive 2001/42/EC). Available at https://eur-lex.europa.eu/legal-content/EN/TXT/?uri=CELEX:52009DC0469.

Faith-Ell, C. and Fischer, T.B. 2021. Strategic environmental assessment in transport planning, in: Fischer, T.B. and González, A. (eds), Handbook on Strategic Environmental Assessment, Cheltenham: Edward Elgar (chapter 11).

Fischer, T. B. 1999. Benefits from SEA application: a comparative review of North West England, Noord-Holland and Brandenburg-Berlin, Environmental Impact Assessment Review 19: 143-73.

Fischer, T. B. 2002. Strategic Environmental Assessment in Transport and Land-use Planning, Earthscan, London.

Fischer, T. B. 2007. Zur internationalen Bedeutung der Umweltprüfung [On the international importance of environmental assessment], UVP Report 21(4): 248-55.

Fischer, T. B. 2020. Editorial - embedding the sustainable development goals (SDGs) in IAPA's remit, Impact Assessment and Project Appraisal, 38(4): 269-71. 
Fischer, T.B. and González, A. 2021. Conclusions: towards a theory of strategic environmental assessment?, in: Fischer, T.B. and González, A. (eds), Handbook on Strategic Environmental Assessment, Cheltenham: Edward Elgar (chapter 27).

Fischer, T. B. and Onyango, V. 2012. Strategic environmental assessment-related research projects and journal articles: an overview of the past 20 years. Impact Assessment and Project Appraisal 30(4): 253-63.

Fischer, T.B. and Retief, F. 2021. Does strategic environmental assessment lead to more environmentally sustainable decisions and action? Reflections on substantive effectiveness, in: Fischer, T.B. and González, A. (eds), Handbook on Strategic Environmental Assessment, Cheltenham: Edward Elgar (chapter 8).

Fischer, T. B., Dalkmann, H., Lowry, M. and Tennøy, A. 2010. The dimensions and context of transport decision making, in Robert Joumard and Henrik Gudmundsson (eds), Indicators of Environmental Sustainability in Transport, pp. 79-102, Les collections de l'Inrets, Paris. http://hal.archives-ouvertes .fr/docs/00/49/28/23/PDF/Indicators_EST_May_2010.pdf.

Fischer, T.B., Muthoora, T. and Sworowski, N. 2021 . Integration through strategic environmental assessment: the case of health in English strategic planning, in: Fischer, T.B. and González, A. (eds), Handbook on Strategic Environmental Assessment, Cheltenham: Edward Elgar (chapter 14).

Fischer, T. B., Potter, K., Donaldson, S. and Scott, T. 2011. Municipal waste management strategies, strategic environmental assessment and the consideration of climate change in England, Journal of Environmental Assessment Policy and Management 13(4): 541-65.

González, A. 2021. Strategic environmental assessment of spatial land use plans, in: Fischer, T.B. and González, A. (eds), Handbook on Strategic Environmental Assessment, Cheltenham: Edward Elgar (chapter 10).

González, A., Bullock, C., Gaughran, A. and Watkin-Bourne, K. 2019. Towards a better understanding of SEA effectiveness in Ireland, Impact Assessment and Project Appraisal 37(3-4): 233-43.

González, A., Gazzola, P. and Onyango, V. 2020. The mutualism of strategic environmental assessment and sustainable development goals, Environmental Impact Assessment Review 82: 1-9.

González, A. and Geneletti, D. 2021. GIS-based strategic environmental assessment, in: Fischer, T.B. and González, A. (eds), Handbook on Strategic Environmental Assessment, Cheltenham: Edward Elgar (chapter 6).

Gosling, J. A. 1999. SEA and the planning process: four models and a report?, International Association for Impact Assessment (IAIA), Conference Proceedings, 19th Annual Meeting, Glasgow 1999, CD-Rom, IAIA, Fargo, ND.

Hayes, S.J. and Fischer, T.B. 2021. Objectives for, of and in strategic environmental assessment, in: Fischer, T.B. and González, A. (eds), Handbook on Strategic Environmental Assessment, Cheltenham: Edward Elgar (chapter 3).

House, P. W. 1974. Diogenes revisited: the search for a valid model, Simulation, 23(4): 117-25.

Jansson, A. H. H. 2000. Strategic environmental assessment for transport in four Nordic countries, in H. Bjarnadóttir (ed.), Environmental Assessment in the Nordic Countries, pp. 39-46, Nordregio, Stockholm.

Jha-Thakur, U. and Rajvanshi, A. 2021. Strategic environmental assessment in India: trends and prospects, in: Fischer, T.B. and González, A. (eds), Handbook on Strategic Environmental Assessment, Cheltenham: Edward Elgar (chapter 25).

Jiliberto, R. 2021. Strategic environmental assessment in Chile: an unfulfilled strategic promise, in: Fischer, T.B. and González, A. (eds), Handbook on Strategic Environmental Assessment, Cheltenham: Edward Elgar (chapter 24).

Koshkar, S., Balfors, B. and Fischer, T.B. 2021. Towards advancing strategic environmental assessment practice: learning from experiences of eight European countries, in: Fischer, T.B. and González, A. (eds), Handbook on Strategic Environmental Assessment, Cheltenham: Edward Elgar (chapter 20).

Marks, A. K., Horvatin, P.J., Leuchner, P.G. and Zar, H. 1980. Draft programmatic environmental impact statement: U.S. Lake Erie natural gas resource development in offshore waters of New York, Pennsylvania and Ohio, Corps of Engineers, Buffalo, NY.

Marot, N., Fischer, T.B., Sykes, O., Golobič, M., Muthoora, T. and González, A. 2021. Territorial impact assessment: a policy assessment-like strategic environmental assessment in action, in: Fischer, T.B. 
and González, A. (eds), Handbook on Strategic Environmental Assessment, Cheltenham: Edward Elgar (chapter 5).

Montaño, M., Tshibangu, G.M and Malvestio, A.C. 2021. Strategic environmental assessment in Brazil: an endangered species?, in: Fischer, T.B. and González, A. (eds), Handbook on Strategic Environmental Assessment, Cheltenham: Edward Elgar (chapter 23).

Morgan, R. and Taylor, N. 2021. Strategic environmental assessment in New Zealand, in: Fischer, T.B. and González, A. (eds), Handbook on Strategic Environmental Assessment, Cheltenham: Edward Elgar (chapter 21).

Morrison-Saunders, A., Sanchez, L. E., Retief, F., Sinclair, J., Doelle, M., Jones, M., Wessels, J. A. and Pope, J. 2019. Gearing up impact assessment as a vehicle for achieving the UN sustainable development goals, Impact Assessment and Project Appraisal 38(2): 113-17.

Mustow, S. E. 2021. Strategic environmental assessment in the water sector, in: Fischer, T. B. and González, A. (eds.). Handbook on Strategic Environmental Assessment, Cheltenham: Edward Elgar (chapter 13).

Noble, B. 2021. Strategic environmental assessment in Canada, in: Fischer, T.B. and González, A. (eds), Handbook on Strategic Environmental Assessment, Cheltenham: Edward Elgar (chapter 19).

OECD. 2012. Strategic environmental assessment in development practice: a review of recent experience. Available at http://www.oecd.org/dac/environment-development/strategic-environmental -assessment-in-development-practice-9789264166745-en.htm.

O’Mahony, C. 2021. Integration of climatic factors into strategic environmental assessments, in: Fischer, T.B. and González, A. (eds), Handbook on Strategic Environmental Assessment, Cheltenham: Edward Elgar (chapter 16).

O'Riordan, T. and Sewell, W. R. D. 1981. Project Appraisal and Policy Review, John Wiley and Sons, Chichester.

Partidário, M. R. 2015. A strategic advocacy role in strategic environmental assessment for sustainability, Journal of Environmental Assessment Policy and Management 17(1): 1550015.

Partidário, M. 2020. Strategic thinking for sustainability (ST4S) in SEA, in: Fischer, T.B. and González, A. (eds), Handbook on Strategic Environmental Assessment, Cheltenham: Edward Elgar (chapter 4).

Porto Silva Cavalcanti, P. M. and La Rovère, E. L. 2011. Strategic environmental assessment of mining activities: a methodology for quantification of cumulative impacts on the air quality, Journal of the Air \& Waste Management Association 61(4): 377-89.

Rehhausen, A., Hanusch, M. and Fischer, T.B. 2021. Multi-project-based strategic environmental assessment: practice in Germany, in: Fischer, T.B. and González, A. (eds), Handbook on Strategic Environmental Assessment, Cheltenham: Edward Elgar (chapter 2).

Retief, F., Steenkamp, C. and Alberts, R. 2021. Strategic environmental assessment in South Africa: 'The Road Not Taken', in: Fischer, T.B. and González, A. (eds), Handbook on Strategic Environmental Assessment, Cheltenham: Edward Elgar (chapter 22).

Sadler, B. and Dusik, J. 2016. European and International Experiences of Strategic Environmental Assessment: Recent Progress and Future Prospects, Taylor and Francis, London.

Scott, P. 2021. Integrating appropriate assessment and strategic environmental assessment in: Fischer, T.B. and González, A. (eds), Handbook on Strategic Environmental Assessment, Cheltenham: Edward Elgar (chapter 15).

Sigal, L. L. and Webb, J. W. 1989. The programmatic environmental impact statement: its purpose and use, The Environmental Professional 11: 14-24.

Slootweg, R. 2021. Ecosystem services in strategic environmental assessment: an integrating concept in a world of silos, in: Fischer, T.B. and González, A. (eds), Handbook on Strategic Environmental Assessment, Cheltenham: Edward Elgar (chapter 17).

Thérivel, R. and González, A. 2021. Strategic environmental assessment effectiveness, in: Fischer, T.B. and González, A. (eds), Handbook on Strategic Environmental Assessment, Cheltenham: Edward Elgar (chapter 7).

Thérivel, R. and Partidário, M. R. 1996. The Practice of Strategic Environmental Assessment, Earthscan, London.

Thérivel, R., Wilson, E., Thompson, S., Heaney, D. and Pritchard, D. 1992. Strategic Environmental Assessment, Earthscan, London. 


\section{Handbook on strategic environmental assessment}

Tiffer-Sotomayor, R., Sánchez-Triana, E., Acerbi, M., Gomes Lima, A. L., Navarro, R., Enriquez, S., Siegmann, K. and Clemente Fern, P. 2015. Legal framework of environmental impact assessment in Latin America, poster presented at IAIA 2015, available at https://conferences.iaia.org/2015/Final -Papers/Tiffer,\%20R\%20et\%20al.\%202015-Poster-\%20LAC-\%20EIA\%20Legal\%20Framework -final-1.pdf.

UNECE [United Nations Economic Commission for Europe]. 2003. Protocol on Strategic Environmental Assessment to the Convention on Environmental Impact Assessment in a Transboundary Context. United Nations Economic Commission for Europe. Available at https://www.unece.org/fileadmin/ DAM/env/eia/documents/legaltexts/protocolenglish.pdf. 